\title{
Grupos de pesquisa em educação física escolar e o periodismo científico: o modus operandi e os interesses dos líderes ${ }^{1}$
}

\author{
Research groups in school physical education and \\ scientific periodism: the mo and the interests of leaders
}

\section{Grupos de investigación en educación física escolar y periodismo científico: modus operandi e intereses de los líderes}

(iD) Jessica Serafim Frasson

Universidade Federal do Rio Grande do Sul (UFRGS), Porto Alegre, Rio Grande do Sul, Brasil jehfrasson@hotmail.com

(iD) Elisandro Schultz Wittizorecki

Universidade Federal do Rio Grande do Sul (UFRGS), Porto Alegre, Rio Grande do Sul, Brasil elisandro.wittizorecki@ufrgs.br

Resumo: Objetivamos compreender os interesses dos líderes dos grupos de pesquisa em Educação Física escolar ao encaminharem suas pesquisas aos periódicos científicos. O desenho metodológico estruturase a partir da pesquisa qualitativa e apresenta a prosopografia como procedimento metodológico, vinculada a entrevistas semiestruturadas e à análise de documentos como ferramentas do processo de obtenção das informações. Consideramos que, devido à estrutura científica instaurada no campo e subcampo acadêmico-científico, a relação de interesse dos líderes com o periodismo acontece mediada pela posição que os agentes ocupam no espaço social. A depender da posição, o modus operandi dos líderes organiza estratégias e ações para seguir operando cientificamente no espaço social.

Palavras-chave: Subcampo acadêmico-científico. Educação Física escolar. Grupo de pesquisa. Periódico científico.

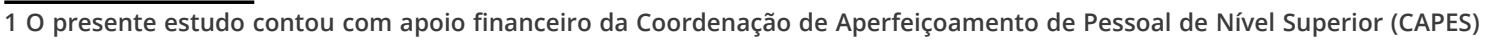
para sua realização. 


\begin{abstract}
We aim to understand the interests of the leaders of research groups in school Physical Education when forwarding their research to scientific journals. As the methodological design, the authors have chosen qualitative research and prosopography as methodological procedures linking semi-structured interviews to the analysis of documents for obtaining information. We considered that due to the scientific structure established in the academic-scientific field and subfield, the relationship of interest of the leaders with the journalism happens mediated by the position that the agents occupy in the social space. Depending on the position, the leaders modus operandi organizes strategies and actions to continue operating scientifically in the social space.
\end{abstract}

Keywords: Academic-scientific Subfield. Physical Education in Schools. Research Groups. Scientific Journals.

Resumen: Nuestro objetivo es comprender los intereses de los líderes de los grupos de investigación en Educación Física escolar al remitir sus investigaciones a revistas científicas. El diseño metodológico se basa en la investigación cualitativa y presenta la prosopografía como un procedimiento metodológico, vinculado a entrevistas semiestructuradas y análisis de documentos como herramientas para el proceso de obtención de información. Consideramos que debido a la estructura científica establecida en el campo y subcampo académico-científico, la relación de interés de los líderes con el periodismo pasa mediatizada por la posición que ocupan los agentes en el espacio social._Dependiendo del cargo, el modus operandi de los líderes organiza estrategias y acciones para seguir operando científicamente en el espacio social.

Palabras clave: Subcampo académico-científico. Educación física escolar. Grupo de investigación. Revistas científicas.

Submetido em: 12-02-2021

Aceito em: 27-05-2021 
Grupos de pesquisa em educação física escolar e o periodismo científico: o modus operandi... Jessica Serafim Frasson • Elisandro Schultz Wittizorecki

\section{Introdução}

Objetivamos, com o presente texto, compreender os interesses dos líderes dos grupos de pesquisa em Educação Física escolar ao encaminharem suas pesquisas para os periódicos científicos. Destacamos que este estudo é fruto de uma pesquisa de doutorado que buscou compreender como os grupos de pesquisa engendram o subcampo acadêmico-científico da Educação Física escolar e que relações são construídas nesse espaço social (FRASSON, 2020). Assim, para dar sequência ao texto, é necessário frisar que o referido subcampo compõe um determinado espaço, denominado por Bourdieu de campo que, segundo o autor, caracteriza-se como um espaço social, de lutas concorrenciais em torno de interesses específicos. Esses interesses são a codificação do seu funcionamento, pois, todo campo é um produto histórico definido por ações individuais e coletivas que se dão dentro de uma certa normatização (BOURDIEU, 1983; 2004).

Os primeiros estudos que compreendem a Educação Física (EF), enquanto um campo, foram realizados por Paiva (1994; 2003). Para a autora, trata-se de um "espaço social de disputas sobre as formas autorizadas de pensar e orientar "educações físicas", campo que se vale das práticas e representações acadêmicas para conferir importância e legitimidade a essas preocupações [...]" (PAIVA, 2004, p. 65).

Também amparados em lentes bourdieusianas, o estudo de Lazzarotti Filho, Silva e Mascarenhas (2014) aponta que o campo da EF se expande, se diversifica e se dinamiza ao incorporar o modus operandi acadêmico-científico. Além de ser um campo de formação e da especificidade pedagógica, a EF passa a ser reconhecida também como um campo científico, principalmente por conta dos cursos de pós-graduação (PG) que demandam aos agentes a incorporação de práticas científicas e a própria produção do conhecimento. Corroborando os autores, compreendemos a EF como um campo acadêmico-científico que é "multidisciplinar e po- 
Grupos de pesquisa em educação física escolar e o periodismo científico: o modus operandi... Jessica Serafim Frasson • Elisandro Schultz Wittizorecki

lifônico", conforme destacam Molina Neto et al. (2006, p. 160); isto é, é engendrado por diferentes áreas de conhecimento e estudo que formam seus subcampos.

Na polifonia da EF, nos dedicamos a estudar o subcampo da Educação Física escolar. Compreendemos como tal, a medida que ele trata de uma das especificidades do campo da EF, concentrando "os agentes e as instituições que produzem, reproduzem ou difundem [...] a ciência" (BOURDIEU, 2004, p. 20), as experiências acadêmicas, os debates, as reflexões e as compreensões sobre a temática que constituem, desenvolvem e consolidam o respectivo subcampo no campo em que se encontra; por fim, é subcampo pois compreende, pedagógica e cientificamente, a cultura corporal de crianças, adolescentes, adultos e idosos nas escolas públicas e privadas. Entendemos, portanto, que não se trata de uma questão de nomenclatura, mas ao contrário, trata-se de um esforço que demarca e determina o lugar das pesquisas em Educação Física escolar no campo da EF (FRASSON, 2020).

\section{Decisões metodológicas}

Trata-se de uma pesquisa de abordagem qualitativa que se apropriou da prosopografia como procedimento metodológico. Segundo Bourdieu (1996), a prosopografia fornece dados objetivados de certo indivíduo, ou seja, as disposições socialmente construídas que o posicionam no mundo social. Sobre a operacionalização da prosopografia, Stone (2011) destaca que ela decorre, em primeiro lugar, da definição de um universo de sujeitos e, posteriormente, da formulação de um grupo de questões padronizadas a serem lançadas ao universo definido.

Desse modo, elegemos os grupos de pesquisa da região sul do Brasil como agentes a serem estudados nesta pesquisa. Eles foram identificados, no site do Diretório de Grupos de pesquisa (DGP) do CNPq, com o descritor "Educação Física escolar" no nome do grupo, no título das linhas de pesquisas, nas palavras-chave, 
Grupos de pesquisa em educação física escolar e o periodismo científico: o modus operandi... Jessica Serafim Frasson • Elisandro Schultz Wittizorecki

nos objetivos das linhas de pesquisas e na repercussão científica do grupo. A busca resultou em 36 grupos de pesquisas, cujos líderes, após essa identificação inicial, foram contatados via e-mail, no qual enviamos uma carta de apresentação da pesquisa e um convite para participação do estudo. Dos 36 líderes selecionados, 17 aceitaram participar.

Para estudar os grupos de pesquisa, lançamos mão da entrevista semiestruturada e da análise de documentos como instrumentos para obtenção das informações. As entrevistas foram realizadas de forma presencial e/ou online, após agendamento prévio com os líderes, entre os meses de outubro e dezembro de 2018, conforme aceite e agenda dos participantes. Elas foram gravadas e depois transcritas, um trabalho que totalizou $13 \mathrm{~h}$ de áudio e 128 páginas de transcrições de material analítico. A análise de documentos, por sua vez, partiu de três documentos primários: (a) o Currículo Lattes dos líderes e demais pesquisadores dos grupos; (b) a página dos grupos no site do DGP (http://lattes.cnpq.br/ web/dgp) e (c) o manual do usuário, documento disponível no site do CNPq (http://lattes.cnpq.br/web/dgp/manual-do-usuario/) que apresenta as funcionalidades básicas do sistema DGP e orienta os usuários quanto à sua utilização.

Para fins de rigor metodológico, a pesquisa também assumiu a responsabilidade ética de preservar a identidade dos participantes. Assim utilizamos nomes fictícios para nos referirmos aos líderes que concederam a entrevista e números para identificar os grupos de pesquisa. Por fim, destacamos que a pesquisa foi submetida à apreciação na Plataforma Brasil (certificado de apresentação para apreciação ética no 16610519.9.0000.5347) e aprovada pelo Comitê de Ética em Pesquisa (CEP) da Universidade Federal do Rio grande do Sul, com o parecer consubstanciado de número 3.627.614. 
Grupos de pesquisa em educação física escolar e o periodismo científico: o modus operandi... Jessica Serafim Frasson • Elisandro Schultz Wittizorecki

\section{Análise das informações}

Ao buscarmos compreender os interesses dos líderes ao encaminharem suas pesquisas para os periódicos científicos, levantamos algumas hipóteses: pela classificação do Qualis periódico; por serem revistas internacionais e, consequentemente, auferirem classificações superiores; pelo prestígio e reconhecimento dos pares; por possuírem um dossiê ou chamada temática; pela celeridade no fluxo de publicação; por possuírem foco e escopo que correspondam às pesquisas realizadas; por possuírem periodicidade em maior escala; ou, por serem gratuitos e não cobrarem taxas de submissão ou de publicação, quando aprovado o artigo, conforme visto recentemente no estudo de Carvalho et al. (2020). Ao que tudo indica, esta última parece ser a tendência de muitos periódicos, dada escassez e/ou cortes de recursos públicos destinados à ciência e tecnologia no país (MASCARENHAS, LAZZAROTTI FILHO, VIANNA, 2019).

Dadas essas possibilidades, dedicamo-nos inicialmente a mapear os periódicos em que os agentes publicaram suas produções nos últimos vinte anos (2000/2020). Constatamos que a produção dos artigos está distribuída por 229 periódicos, sendo que 70\% contam com um único artigo de autoria/coautoria dos líderes no período pesquisado. Embora não seja o nosso objetivo, é preciso pontuar que esses dados revelam uma certa dispersão do conhecimento produzido e merecem mais estudos, uma vez que não há, por exemplo, um periódico em que todos os líderes tenham publicado ao menos um artigo.

Considerando que nenhum dos periódicos científicos possui artigos de autoria/coautoria de todos os líderes, buscamos identificar se há, uma possível concentração do conhecimento produzido pelos agentes nesses espaços. Para isso, apresentamos no quadro a seguir os periódicos que concentraram publicações de cinco ou mais líderes dos grupos de pesquisa entrevistados ao longo dos últimos vinte anos, suas respectivas classificações no sistema 
Grupos de pesquisa em educação física escolar e o periodismo científico: o modus operandi... Jessica Serafim Frasson • Elisandro Schultz Wittizorecki

Qualis² periódico e o número de artigos publicados pelos líderes em cada uma dessas revistas.

\section{Quadro 01. Periódicos que concentram publicações de cinco ou mais líderes entre os anos 2000 a 2020.}

\begin{tabular}{|l|c|c|c|}
\hline \multicolumn{2}{|r|}{ Revistas e seus respectivos Qualis na Educação Física ${ }^{3}$} & $\begin{array}{c}\text { No de líderes } \\
\text { que publica- } \\
\text { ram em cada } \\
\text { revista }\end{array}$ & $\begin{array}{c}\text { No de artigos } \\
\text { publicados } \\
\text { em cada } \\
\text { revista }\end{array}$ \\
\hline Lecturas Educación Física y Deportes (EFdeportes) & C & 13 & 103 \\
\hline Motrivivência (UFSC) & B2 & 10 & 26 \\
\hline Movimento (ESEFID/UFRGS) & A2 & 9 & 40 \\
\hline Pensar a Prática (UFG) & B2 & 9 & 25 \\
\hline Revista Brasileira de Ciências do Esporte (RBCE) & B1 & 9 & 29 \\
\hline Kinesis (UFSM) & B4 & 8 & 18 \\
\hline Journal of Physical Education (UEM) & B1 & 8 & 17 \\
\hline Conexões (Unicamp) & B4 & 7 & 10 \\
\hline FIEP Bulletin & C & 6 & 21 \\
\hline Revista Brasileira de Atividade Física e Saúde (RBAFS) & B2 & 6 & 19 \\
\hline Revista Biomotriz (UNICRUZ) & B5 & 5 & 22 \\
\hline Cinergis (UNISC) & B5 & 5 & 13 \\
\hline Revista Didática Sistêmica (FURG) & B4 & 5 & 8 \\
\hline Coleção Pesquisa em Educação Física & B4 & 5 & 9 \\
\hline Licere (UFMG) & B2 & 5 & 9 \\
\hline Caderno de Educação Física e Esporte (UNIOESTE) & B4 & 5 & 12 \\
\hline Revista Brasileira de Educação Física e Esporte (USP) & B1 & 5 & 6 \\
\hline
\end{tabular}

Fonte: Frasson (2020, p. 192).

Conforme informações apresentadas no Quadro 1, acima, constatamos que das 229 revistas, apenas 17 - que correspondem a 7,5\% de todos os periódicos -, concentram publicações de cinco ou mais líderes no período investigado. Também é possível 2 O sistema Qualis periódico foi desenvolvido pela Coordenação de Aperfeiçoamento de Pessoal de Nível Superior (CAPES) para
avaliar a produção científica dos programas acadêmicos de pós-graduação (CAPES, 2019).
3 Todas as classificações apresentadas ao longo do texto correspondem à classificação de periódicos do quadriênio de 2013-
2016 . A consulta foi realizada na plataforma Sucupira pelo link: https://sucupira.capes.gov.br/sucupira/public/consultas/coleta/veiculoPublicacaoQualis/listaConsultaGeralPeriodicos.jsf, no dia 10 de agosto de 2020. 
Grupos de pesquisa em educação física escolar e o periodismo científico: o modus operandi... Jessica Serafim Frasson • Elisandro Schultz Wittizorecki

observar que o número de artigos publicado em cada revista e, nesse aspecto, um periódico que merece destaque é o Lecturas Educación Física y Deportes (EFdeportes), que concentrou o maior número de artigos publicados pelos líderes, e também o maior número de líderes, pois, 13 dos 17 líderes publicaram ao menos um artigo ao longo do período analisado.

Cotejando as informações do quadro, com os estudos de Antunes et al. (2005), Betti, Ferraz, Dantas (2011), Bracht et al. (2011) e Wiggers et al. (2015), que tratam sobre a produção do conhecimento em EF escolar nos periódicos científicos, é possível identificar que revistas como a Movimento, a Revista Brasileira de Ciências do Esporte, a Motrivivência e a Pensar a Prática, historicamente, "apresentam percentuais mais elevados de produção em relação ao tema da Educação Física Escolar" (BRACHT, et al. 2011, p. 32). Entendemos que essa é uma tendência que se mantém atualmente, pois essas revistas, além de veicularem um numero significativo de pesquisas sobre o tema, concentram o maior numero de líderes que publicam artigos nos últimos 20 anos.

Interpretamos que isso ocorre devido à representatividade que esses periódicos possuem como veículos de divulgação da produção do conhecimento no campo e subcampo. Além disso, são revistas reconhecidas pelos agentes do espaço social, por conta da suas estratificações no sistema Qualis periódico; elas compõem o conjunto das poucas revistas que veiculam, majoritariamente, estudos referentes às demandas pedagógicas e sociais da Educação Física escolar e são de classificação superior, ou seja, de maior rentabilidade científica. Mas, para entender melhor essaúltima questão, eainda, para interpretarmos os possíveis interesses dos líderes ao encaminharem suas pesquisas aos periódicos, é necessário compreender como o periodismo científico está organizado na estrutura social.

De acordo com a CAPES (2019), os periódicos são organizados hierarquicamente, estratificados em 9 níveis: A1, A2, B1, B2, B3, B4, $B 5, C$ e NPC4. No campo científico, para fins de ranqueamento e

4 Não periódicos científicos. “Enquadra-se nesta definição veículos que não atendem à definição de periódico científico, tais como magazines, diários, anais, folhetos, conferências e quaisquer outros que se destinam à divulgação" (CAPES, 2019, p. 4). 
Grupos de pesquisa em educação física escolar e o periodismo científico: o modus operandi... Jessica Serafim Frasson • Elisandro Schultz Wittizorecki

disputa, esses níveis são transubstanciados em pontos, sendo: os periódicos de estrato superior (A1, A2, B1 e B2) os mais rentáveis 100, 80, 60 e 40 pontos; e, os periódicos de estrato inferior (B3, B4, B5, C), os menos rentáveis - 20, 10, 05 e 0 pontos, respectivamente. No processo de avaliação, os periódicos conferem aos artigos publicados e a seus respectivos autores, determinada rentabilidade, conforme sua estratificação e classificação.

Sobre a publicação em periódicos na estrutura científica estabelecida, Silva (2009, p. 119) nos lembra que: "quanto melhor situado na hierarquia do Qualis, maior o poder de atração e maiores as chances de influenciar na captação de financiamentos". Além disso, na lógica estabelecida pelos sistemas de avaliações e pelos órgãos de financiamento de pesquisa, a maximização e acumulação desse capital específico (os pontos) é convertida no principal critério para as concessões de bolsas, de recursos financeiros, de disputas em vagas para concursos públicos ou em pleitos para os cursos de mestrado e doutorado, conforme visto em Manoel e Carvalho (2011). Por isso, em alguns casos, nas práticas científicas dos líderes, há a propensão a investir em um determinado capital, acumulando-o (ORTIZ, 1983).

Ao mapearmos a classificação de todos os 229 periódicos em que os líderes publicaram suas produções nos últimos 20 anos, verificamos que $24 \%$ das revistas possuem classificação superior; 32\% classificação inferior; 33\% não possui classificação em Educação Física, mas são classificados em outras áreas de conhecimento, a saber: educação, ensino, interdisciplinar, saúde coletiva e medicina; e, $11 \%$ não possuem classificação em nenhuma área de conhecimento. Esses dados indicam que os líderes têm publicado em periódicos de distintas estratificações; contudo, identificamos também que nem todos os líderes publicaram em revistas de classificação superior.

Levando em consideração a estrutura do campo e subcampo acadêmico-científico, observamos que a relação de interesse entre o periodismo científico e os grupos de pesquisa em Educação Física escolar acontece de diferentes formas, a depender, inclusi- 
Grupos de pesquisa em educação física escolar e o periodismo científico: o modus operandi... Jessica Serafim Frasson • Elisandro Schultz Wittizorecki

ve, da posição que os líderes dos grupos ocupam no espaço social. Na sequência, apresentaremos as evidências empíricas que, em nossa compreensão, expressam os possíveis e distintos interesses desses agentes ao encaminharem suas produções para os periódicos científicos.

Iniciemos com o periódico científico European Journal of Sport Science, que está vinculado ao Colégio Europeu de Ciências do Esporte e classificado no Qualis periódico como A1; dos 17 líderes entrevistados, apenas Mário, líder do grupo 20, publicou nessa revista. Mário é um pesquisador cuja formação acadêmico-científica é atravessada pelo paradigma da aptidão física, e vem se consolidando em uma forma de fazer pesquisa e de entender a Educação Física escolar vinculada aos preceitos da atividade física e da saúde. Isso fica evidente em sua entrevista, quando diz: "defendemos que as aulas de EF tenham 15 minutos de formação corporal [...] voltados para a atividade física [...] pois eles são capazes de alterar o perfil atual de saúde das crianças" (Mário, líder do grupo 20). Essa compreensão dialoga e vai ao encontro do foco e escopo do referido periódico, que visa a publicizar, majoritariamente, estudos e pesquisas vinculados às ciências naturais, conforme informações obtidas no seu site5; revelando que o interesse do líder pode estar relacionado tanto a rentabilidade como a própria temática da revista.

Importante frisar que Mário é bolsista produtividade PQ1D do CNPq6, indicando um altíssimo nível de produção científica, pois os critérios para concessão desse tipo de bolsa passam, preferencialmente, pelos índices de produção. Ser bolsista produtividade, na lógica científica estabelecida, significa emplacar uma espécie de "certificado de produtividade", uma dimensão de fomento que, segundo Molina Neto et al. (2006, p. 157), estabelece "um marco 'oficial' de pesquisa, na medida em que se trata de um órgão go-

\footnotetext{
5 Disponível em: https://www.tandfonline.com/action/journallnformation?show=aimsScope\&journalCode=tejs20. Acesso em: 11 ago. 2020.

6 A bolsas produtividades são “destinada[s] aos pesquisadores que se destaquem entre seus pares, valorizando sua produção científica segundo critérios normativos, estabelecidos pelo CNPq, e específicos, pelos Comitês de Assessoramento (CAs) do CNPq". Informações obtidas no site do CNPq, pelo link http://www.cnpq.br/documents/10157/5f43cefd-7a9a-4030-945e-4a0fa10a169a. Acesso em: 24 ago. 2020.
} 
Grupos de pesquisa em educação física escolar e o periodismo científico: o modus operandi... Jessica Serafim Frasson • Elisandro Schultz Wittizorecki

vernamental que investe, estabelece um ranking e legitima determinados campos e métodos, [...] do fazer científico".

Em termos bourdieusianos, um artigo publicado no periódico European Journal of Sport Science, confere a Mário a maximização do seu capital científico; por conseguinte, o líder, o grupo e as pesquisas que realizam são prestigiadas e reconhecidas pelos pares, pelas instituições ensino e de fomento a pesquisa por estarem alinhados ao paradigma científico que historicamente domina o campo e subcampo.

Diferente de Mário, os líderes credenciados em programas de PG que decidem pesquisar temas contra-hegemônicos, isto é, que se distanciem dos princípios naturais e biomédicos que estruturam o campo científico, recorrentemente encontram e relatam dificuldades em vincular suas pesquisas a periódicos de maiores estratificações. A evidência empírica que sustenta essa assertiva pode ser exemplificada com um trecho da entrevista realizada com Márcia, líder do grupo 22:

Sentimos uma grande dificuldade para publicação de artigos, não pela falta de produção, mas pela escassez de revistas na nossa área, a demora nas avaliações e publicações dos textos... sem falar no desrespeito com as pesquisas que fazemos, que muitas vezes não é entendida como pesquisa, pela questão cartesiana de quem entende e diz o que é ou não pesquisa, ou o que e como pesquisar.

A denúncia de Márcia, em relação à escassez de revistas que privilegiem, em seu foco e escopo, as pesquisas em Educação Física escolar vinculadas aos preceitos das ciências humanas e sociais, encontra força empírica nos dados da realidade. Identificamos que dos 56 periódicos com Qualis superior na EF (A1, A2, B1 e B2), $73 \%$ possuem foco e escopo voltados para as ciências naturais e biomédica. Esse parece ser um problema histórico no campo e subcampo, uma vez que Betti, Ferraz e Dantas (2011), ao analisarem a produção do conhecimento em Educação Física escolar nos 
Grupos de pesquisa em educação física escolar e o periodismo científico: o modus operandi... Jessica Serafim Frasson • Elisandro Schultz Wittizorecki

periódicos científicos, também sinalizaram uma tendência de redução de periódicos que apresentam em suas políticas editoriais espaço para as publicações que tratem das demandas pedagógicas que envolvam a EF escolar. Essa carência de periódicos e a alta demanda de artigos - por conta da lógica produtivista instaurada nos programas de PG, nos editais de financiamento científico e bolsa de estudos -, se expressa, também, no longo período em que os artigos submetidos ficam em avaliação.

Além disso, é preciso destacar que a classificação do periódico científico varia de acordo com a área de conhecimento, isso significa que o mesmo periódico pode ser classificado como A1 na Educação e B5 na EF, por exemplo. Isso pode gerar ainda mais dificuldade para aqueles líderes que buscam outras possibilidades de publicação dada a escassez de revistas na área, como destacou Márcia em sua entrevista -, ou, que estão credenciados em outros programas que não a EF, caso de Patrícia, líder do grupo 15, que está credenciada a um PPG em Gerontologia. Segundo a líder: "quando vamos publicar algum artigo tem que olhar quantos pontos tem na gerontologia, na EF e quantos na educação, é um quebra-cabeça quase impossível de fazer" (Patrícia, líder do grupo 15).

Deste modo, interpretamos que o modus operandi dos líderes dos grupos de pesquisa que estão vinculados à pós-graduação e que pesquisam/estudam temáticas consideradas marginais, tomam outros caminhos em relação ao periodismo científico. Por estarem em condições de produção e publicização científica desiguais - dada realidade científica instaurada no campo e subcampo -, observamos que ao encontrarem dificuldades em publicar suas produções em revistas de maior estratificação, os líderes criam alternativas de ações e estratégias de disputas para seguirem operando cientificamente. Pois, como afirma Gabriela, líder do grupo 03: "é um jogo insano, que você pode ir contra, mas não pode jogar contra, temos que criar estratégias para se manter na disputa (Gabriela, líder do grupo 03).

Assim, identificamos que os periódicos de menor estratificação, em alguns casos, passam a ser o alvo de interesse dos líderes 
Grupos de pesquisa em educação física escolar e o periodismo científico: o modus operandi... Jessica Serafim Frasson • Elisandro Schultz Wittizorecki

dos grupos de pesquisa, pois é de "grão a grão, que a galinha enche o papo", é de ponto a ponto, que os professores e professoras se mantêm na disputa acadêmico-científica. Essa reflexão ganha força empírica com um trecho da entrevista realizada com Lucas, líder do grupo 19: "tenho uma amiga que diz o seguinte: Há os trabalhos que produzimos porque fazem sentido para nossa vida acadêmica e os trabalhos que são para dar ração pro Lattes..."; alimentar o Lattes faz parte do modus operandi dos líderes.

O modus operandi é uma "espécie de sentido do jogo científico que faz com que [os agentes] faça[m] o que é preciso fazer no momento próprio" (BOURDIEU, 1989, p. 23, grifo nosso). Por isso, "não há 'escolha' científica [...] que não seja uma estratégia política" (BOURDIEU, 1996, p. 146) de sobrevivência, de resistência e de disputa. Elas são orientadas por interesses e intencionalidades, que, nesse caso, materializam-se em encaminhar as produções para periódicos de distintas classificações; acumulando pontos e, buscando manter-se credenciados nos respectivos programa de $P G$, pois, "[...] sem pesquisa e publicações, não conseguimos nos manter ou muito menos entrar no mundo da pós" (Paulo, líder do grupo 23); e, conforme destaca Marcos, líder do grupo 21: "quando no jogo, tem que jogar e ainda estamos aqui... então, quando vai escrever alguma coisa e o texto não tem uma capitalização, e é isso mesmo, capitalismo puro... pensa bem e escreve um artigo".

A guisa de reflexão, registramos que a busca do "ponto a ponto" é reflexo de uma política produtivista adotada pelos órgãos de financiamento de pesquisa que, conforme destacou Rego (2014), tem causado muitos problemas não apenas ao periodismo científico, como também aos líderes envolvidos pela "lógica credencialista" dos PPGs (BRANDÃO, 1986). Ainda que os líderes criem suas estratégias para alimentar o Lattes, "enchendo o papo de grão a grão", estão sempre em desvantagem, visto que as revistas de menor classificação são menos rentáveis, e por isso eles precisam publicar mais, capitalizando os pontos necessários para seguir nas disputas científicas do campo e subcampo. 
Grupos de pesquisa em educação física escolar e o periodismo científico: o modus operandi... Jessica Serafim Frasson • Elisandro Schultz Wittizorecki

Em contraste aos exemplos que apresentamos até o presente momento, identificamos uma certa despreocupação em relação à rentabilidade dos artigos publicados por parte dos líderes dos grupos de pesquisa que não estão credenciados a nenhum PPG. Por isso, observamos que os periódicos de menor classificação também são alvo de interesses desses agentes. Para evidenciar empiricamente a constatação, apresentamos o exemplo de Helena, líder do grupo 36, que é professora de EF de uma faculdade privada e da Educação Básica na rede estadual da cidade onde reside.

\begin{abstract}
Não damos prioridade às revistas A1, B1. Não é que não achamos importante, mas é porque não estamos ligados a nenhum programa de pós-graduação. [...] Publicamos em revista de "Qualis ruim" no sentido de avaliação, de pontos... pois isso não importa muito para nós. [...] Professor da escola que ir em eventos, aprender atividades novas, conversar sobre o dia a dia, ele vai no Meeting, no Jopef, fazer cursos, publicar sua experiência nesses locais sabe [...] (Helena, líder do grupo 36).
\end{abstract}

Ao analisar o conhecimento produzido por Helena e demais agentes do grupo 36, identificamos que os artigos científicos são publicados em revistas de Qualis inexistente e/ou de menor estratificação - caso da Fiep Bulletin, revista científica da Federação Internacional de EF (FIEP), de classificação C. A referida federação organiza congressos nacionais e internacionais no campo da EF e vincula os trabalhos apresentados nesses espaços aos números e volumes de publicações da revista. Mais que publicar suas pesquisas em determinados periódicos, Helena e seu respectivo grupo buscam compartilhar suas experiências e socializar o conhecimento construído em congressos e eventos científicos.

Assim como Helena, é possível identificar outros líderes que também buscam veicular suas produções em revistas de menor classificação por não estarem vinculados a nenhum PPG, não necessitando da acumulação dos pontos. É o caso de Rosa, Bete, Ana e João, líderes dos grupos 07, 11, 18 e 28; apontando indícios de 
Grupos de pesquisa em educação física escolar e o periodismo científico: o modus operandi... Jessica Serafim Frasson • Elisandro Schultz Wittizorecki

que há, no subcampo, líderes e grupos de pesquisa que constroem seu conhecimento sobre a Educação Física escolar à margem das classificações da CAPES. Compreendemos, então, que os interesses desses agentes são mediados pelas relações que constroem e pelas posições que ocupam no interior do seu próprio espaço social.

A relação com o periodismo científico, nesses casos, acontece de modo um pouco diferente. Por isso, interpretamos que a rentabilidade conferida pelo Qualis periódico aos artigos científicos não é o interesse principal desses agentes, que tem se dedicado a publicizar suas pesquisas, resultantes de experiências pedagógicas diversas, tais como as orientações de trabalho de conclusão de curso, de pesquisas de iniciação científica e/ou de projetos de extensão, por exemplo. Nas palavras de Helena, "são produções mais caseiras, fruto das pesquisas cotidianas realizadas nas escolas da região". Nesse caso, os eventos e congressos são entendidos como espaços para socializar e publicizar o conhecimento que constroem.

Por fim, e para além do Qualis periódico, identificamos que as temáticas de pesquisa/estudo dos agentes também podem indicar, em alguns casos, os periódicos em que os líderes têm investido seus interesses. Como exemplo, destacamos Patrícia, líder do grupo 15, que foi a única dos 17 líderes a publicar na Revista Estudos Feministas, que tem como foco e escopo as questões de gênero e feminismos7; em sua entrevista, Patrícia afirmou que o grupo tem se dedicado a estudar e pesquisar as temáticas de "corpo, gênero e sexualidade". Outro exemplo pode ser evidenciado com a Revista Brasileira de Atividade Física e Saúde, onde quatro (Gabriel, Ana, Mário e Paulo, líderes dos grupos 09, 18, 20 e 23) dos seis líderes que possuem artigos publicados nesse periódico estão envolvidos diretamente com as temáticas de estudo vinculadas, majoritariamente, às questões de saúde e atividade física dos escolares.

7 Informações obtidas no site da revista pelo link, disponível em: https://periodicos.ufsc.br/index.php/ref/about/editorialPolicies\#focusAndScope. Acesso em: 28 ago. 2020. 
Grupos de pesquisa em educação física escolar e o periodismo científico: o modus operandi... Jessica Serafim Frasson • Elisandro Schultz Wittizorecki

\section{Considerações finais}

A guisa de finalização, retomamos o objetivo do estudo que buscou compreender os interesses dos líderes dos grupos de pesquisa em Educação Física escolar ao encaminharem suas pesquisas aos periódicos científicos. Consideramos que, devido à estrutura científica instaurada no campo e subcampo acadêmico-científico, a relação de interesse dos líderes com o periodismo acontece mediada pela posição que os agentes ocupam no espaço social.

Os dados da realidade nos permitem destacar que a relação de interesse dos líderes credenciados aos programas de pós-graduação stricto sensu se distinguem daqueles líderes que não estão vinculados a nenhum programa de PG. Consideramos que isso ocorre, principalmente, pela pressão da lógica credencialista instaurada nos programas, que se debruça no produtivismo e na capitalização científica. Já os que não possuem vínculo com PPGs, não sofrem as mesmas pressões e exigências de publicações que aqueles que estão credenciados e que precisam se manter nas disputas científicas. Assim, identificamos uma certa despreocupação e até desinteresse desses agentes em relação à classificação dos periódicos, encaminhando suas pesquisas as revistas de menor estratificação ou de Qualis inexistente.

Igualmente, consideramos que os interesses dos líderes que estão credenciados a PPGs stricto sensu também se distinguem dependendo das temáticas de estudo e pesquisa que desenvolvem no espaço social. Contudo, para esses agentes, a classificação e a estratificação dos periódicos é um ponto importante, uma vez que a rentabilidade conferida às pesquisas publicadas contribui para a sua manutenção nos respectivos programas, captação ou renovação de bolsas, além de conferir prestígio e legitimidade aos agentes sociais.

Nesse sentido, verificamos que aqueles que pesquisam/estudam, temáticas consideradas hegemônicas, ou seja, que se aproximam dos princípios naturais e biomédicos, tendem a ter menos 
Grupos de pesquisa em educação física escolar e o periodismo científico: o modus operandi... Jessica Serafim Frasson • Elisandro Schultz Wittizorecki

dificuldade em vincular suas pesquisas aos periódicos científicos mais qualificados; isso ocorre pois o número de revistas que contemplam essas temáticas é significativamente maior do que os periódicos que veiculam estudos relacionados às demandas pedagógicas e sociais da Educação Física escolar. Além disso, muitos dos periódicos que se aproximam da compreensão dominante de ciência estão melhor classificados, segundo a organização hierárquica do sistema Qualis, rendendo maior capitalização aos líderes que neles publicam. De outro modo, as evidências empíricas nos permitem considerar que os líderes dos grupos de pesquisa, que estudam e pesquisam temáticas consideradas marginais pela estrutura científica que organiza o campo e o subcampo, apresentam maiores dificuldades em publicar suas pesquisas e, por isso, constroem outras relações de interesses com periodismo científico. O número reduzido de revistas, e a classificações que elas possuem no espaço social, faz com que esses agentes tenham que desenvolver estratégias de disputas e resistências.

Por fim, consideramos que "o campo científico é sempre o lugar de uma luta, mais ou menos desigual, entre agentes desigualmente dotados de capital específico e, portanto, desigualmente capazes de se apropriarem do produto do trabalho científico (BOURDIEU, 1983, p. 136, grifos do autor). Deste modo, compreendemos que o modus operandi dos líderes dos grupos de pesquisa produz interesses que são, antes de tudo, político-epistemológicos, encharcados de intencionalidades e, portanto, de compromisso com um determinado fazer científico.

\section{Referências Bibliográficas}

ANTUNES, Fabia Helena Chiorboli et al. Um retrato da pesquisa brasileira em Educação Física escolar: 1999 - 2003. Motriz, Rio Claro, v. 11, n. 3, p. 179-184, set./dez. 2005.

BETTI, Mauro; FERRAZ, Osvaldo Luiz Luiz; DANTAS Eduardo Pinto Basto Tourinho. Educação Física Escolar: estado da arte 
Grupos de pesquisa em educação física escolar e o periodismo científico: o modus operandi... Jessica Serafim Frasson • Elisandro Schultz Wittizorecki

e direções futuras. RBCE, São Paulo, v. 25, p. 105-15, n. esp. 105, dez. 2011.

BOURDIEU, Pierre. O campo científico. In: ORTIZ, Renato (Org.). A sociologia de Pierre Bourdieu. São Paulo: Ed. Ática, p. 122-155, 1983.

BOURDIEU, Pierre. O poder simbólico. Rio de Janeiro: Bertrand Brasil, 1989.

BOURDIEU, Pierre. Razões práticas: sobre a teoria da ação. São Paulo: Papirus, 1996.

BOURDIEU, Pierre. Os usos sociais da ciência: por uma sociologia clínica do campo científico. São Paulo: Editora UNESP, 2004.

BRACHT, Valter et al. A educação física escolar como tema da produção do conhecimento nos periódicos da área no Brasil (1980-2010): parte I. Porto Alegre. Movimento, Porto Alegre, v. 17, n. 2, p. 11-34, 2011.

BRANDÃO, Zaia. A pesquisa em educação e o impacto do crescimento da pós-graduação no Brasil. Em Aberto, Brasília, ano 5, n. 31, p. 25-30, ago./set. 1986.

CARVALHO, Moisés Vieira de. et al. A escolha do periódico científico sob a perspectiva financeira: análise do estrato A1 na área 21. RBCE, Brasil, 2020.

CAPES, Coordenação de Aperfeiçoamento de Pessoal de Nível Superior. Documento de Área. Área 21 - Educação Física. Brasília, 2019. Disponível em: https://www.gov.br/capes/pt-br/centrais-de-conteudo/educacao-fisica-pdf. Acesso em: set. 2019.

FRASSON, Jessica. Epistemologias da Educação Física escolar: do alto da torre de marfim ao chão da realidade concreta. 2020. 225 f. Tese (Doutorado em Educação Física) - Universidade Federal do Rio Grande do Sul, Escola de Educação Física - Porto Alegre, RS, 2020.

LAZZAROTTI FILHO, Ari; SILVA, Ana Marcia; MASCARENHAS, Fernando. Transformações contemporâneas do campo acadêmico-científico da educação física no Brasil: novos habitus, modus 
Grupos de pesquisa em educação física escolar e o periodismo científico: o modus operandi... Jessica Serafim Frasson • Elisandro Schultz Wittizorecki

operandi e objetos de disputa. Movimento, Porto Alegre, v. 20, n. esp., p. 67-80, 2014.

MANOEL, Edson de Jesus; CARVALHO, Yara Maria de. Pósgraduação na educação física brasileira: a atração (fatal) para a biodinâmica. Revista de Educação e Pesquisa, São Paulo, v. 37, n. 2, p. 389-406, 2011.

MASCARENHAS, Fernando; LAZZAROTTI FILHO, Ari; VIANNA, Lauro Casqueiro. Crise no financiamento à pesquisa e desafios para RBCE. RBCE, Brasília, v. 41, ed. 3, jul. a set., 2019.

MOLINA NETO, Vicente et al. Reflexões sobre a produção do conhecimento em Educação Física e ciências do Esporte. RBCE, Campinas, v. 28, n. 1, p. 145-165, set., 2006.

ORTIZ, Renato (Org.). A sociologia de Pierre Bourdieu. São Paulo: Ed. Ática, 1983.

PAIVA, Fernanda Simone Lopes de. Ciência e Poder simbólico no colégio Brasileiro de Ciências do Esporte. 1994.

Dissertação (Mestrado em Educação Física) - Universidade Federal do Espírito Santo, Vitória, 1994.

PAIVA, Fernanda Simone Lopes de. Constituição do campo da Educação Física no Brasil: ponderações acerca de sua especificidade e autonomia. In: BRACHT, Valter.; CRISORIO, Ricardo. (Orgs.). A Educação Física no Brasil e na Argentina: identidade, desafios e perspectivas. Campinas/SP: Autores Associados, p. 63-80, 2003.

PAIVA, Fernanda Simone Lopes de. Notas para pensar a Educação Física a partir do conceito de campo. Perspectiva, Florianópolis, v. 22, n. Especial, p. 51-82, jul./ dez., 2004.

REGO, Teresa Cristina. Produtivismo, pesquisa e comunicação científica: entre o veneno e o remédio. Educação e Pesquisa, São Paulo, v. 40, n. 2, p. 325-346, abr./jun., 2014.

SILVA, Antonio Ozaí da. A sua revista tem Qualis? Mediações, Londrina, v. 14, n. 1, p. 117-124, jan./jun., 2009. 
Grupos de pesquisa em educação física escolar e o periodismo científico: o modus operandi... Jessica Serafim Frasson • Elisandro Schultz Wittizorecki

STONE, Lawrence. Prosopografia. Rev. Sociol. Polít., Curitiba, v. 19, n. 39, p. 115-137, jun. 2011.

WIGGERS, Ingrid Dittrich et al. Um "raio-X" da produção do conhecimento sobre Educação Física escolar: Análise de periódicos de 2006 a 2012. Movimento, Porto Alegre, v. 21, n. 3., p. 831-845, jul./set. De 2015.

\section{Publisher}

Universidade Federal de Goiás. Faculdade de Educação Física e Dança. Publicação no Portal de Periódicos UFG. As ideias expressadas neste artigo são de responsabilidade de seus autores, não representando, necessariamente, a opinião dos editores ou da universidade. 